\title{
Cytoplasmic ERa and NFkB Promote Cell Survival in Mouse Mammary Cancer Cell Lines
}

\author{
Emily Smart ${ }^{1}$ • Luis H. Alejo ${ }^{1}$. Jonna Frasor ${ }^{1}$
}

Received: 21 November 2019 / Accepted: 16 January 2020 / Published online: 1 February 2020

(C) Springer Science+Business Media, LLC, part of Springer Nature 2020

\begin{abstract}
There is a desperate need in the field for mouse mammary tumors and cell lines that faithfully mimic estrogen receptor (ER) expression and activity found in human breast cancers. We found that several mouse mammary cancer cell lines express ER but fail to demonstrate classical estrogen-driven proliferation or transcriptional activity. We investigated whether these cell lines may be used to model tamoxifen resistance by using small molecule inhibitors to signaling pathways known to contribute to resistance. We found that the combination of NFKB inhibition and ER antagonists significantly reduced cell proliferation in vitro, as well as growth of syngeneic tumors. Surprisingly, we found that ER was localized to the cytoplasm, regardless of any type of treatment. Based on this, we probed extra-nuclear functions of ER and found that co-inhibition of ER and NFKB led to an increase in oxidative stress and apoptosis. Together, these findings suggest that cytoplasmic ER and NFKB may play redundant roles in protecting mammary cancer cells from oxidative stress and cell death. Although this study has not identified a mouse model with classical ER activity, cytoplasmic ER has been described in a small subset of human breast tumors, suggesting that these findings may be relevant for some breast cancer patients.
\end{abstract}

Keywords Estrogen receptor $\cdot$ Mouse $\cdot$ Mammary cancer $\cdot$ NFKB $\cdot$ Tamoxifen

\section{Introduction}

Breast cancer is the second most diagnosed cancer in females behind skin cancer and is expected to be responsible for more than 41,000 deaths in 2019. The majority of breast cancers, around $75 \%$, express estrogen receptor alpha $(\mathrm{ER} \alpha)$ and are diagnosed as estrogen receptor positive (ER+) [1]. The growth and survival of these tumors are stimulated by estrogen binding to $\mathrm{ER} \alpha$. Thus, treatments that disrupt or inhibit estrogen signaling, such as tamoxifen or aromatase inhibitors, are routinely used to treat women with ER+ breast tumors. Despite the success of these therapies, between 30 and $50 \%$ of ER+ breast cancers are expected to recur, frequently as more

Electronic supplementary material The online version of this article (https://doi.org/10.1007/s12672-020-00378-2) contains supplementary material, which is available to authorized users.

Jonna Frasor

jfrasor@uic.edu

1 Department of Physiology and Biophysics, College of Medicine, University of Illinois, 835 S. Wolcott, E202 MSB, MC901, Chicago, IL 60612, USA aggressive, metastatic, and therapy-resistant disease [2]. Consequently, the majority of breast cancer deaths each year result from ER+ breast cancer. Clearly, new therapeutic targets and strategies are needed to combat recurrent $\mathrm{ER}+$ disease.

Current approaches used to study hormone-dependent breast cancer are highly reliant on ER+ breast cancer cell lines grown in culture or as xenograft tumors in immunocompromised mice. Cell lines, such as MCF-7 and T47D, are the most widely used models to study ER+ breast cancer and have advanced our mechanistic understanding of estrogen and tamoxifen action tremendously. Cell line-derived xenografts are the most commonly used in vivo model to study breast cancer, due to their simplicity, low cost, and ease of cell line manipulation to study a protein/pathway of interest. However, these models fail to capture the complex tumor microenvironment and typical disease progression seen in human tumors. A more sophisticated adaptation of the xenograft model has been developed-mouse intraductal (MIND) models. Here, cells are injected into the ducts of immunocompromised mice rather than the fat pad, in order to mimic the normal epithelial environment. Brisken and colleagues showed that MCF-7 cells injected intraductally more closely resembled ER+ luminal disease characteristics than tumors injected into the fat pad 
and that tumors grew under physiological hormone levels without E2 supplementation [3].

Another approach to more closely model patient disease is patient-derived xenografts (PDX), where human tumor cells or pieces of tissue are engrafted into immunocompromised mice. This approach has the advantages of closely mimicking human breast cancer, inclusion of a stromal component, and retention of therapy response and histopathological features [4]. However, one major disadvantage is that the majority of PDX models are derived from more aggressive ER- phenotypes [5] so are often not useful for studying ER+ disease. One approach that can combine the advantages of cell lines and PDXs are patient-derived organoids (PDO). These have the versatility and amenability of cell lines, such as ability to be genetically manipulated and cultured indefinitely, with the clinical relevance PDX models, and show great promise for both research tools and modeling patient disease. Generation of ER+ PDOs has been more successful than with PDX. A 2017 study by Sachs et al. generated a biobank of organoids from patient breast tumors [6]. These organoids represented all molecular subtypes of breast cancer without bias and broadly matched the original tumor, suggesting minimal loss of oncogenic driver expression. ER+ organoids represented a large proportion of the organoids generated, showing much greater success rate than establishing ER+ PDX models. Importantly, when a response to tamoxifen was observed in patients, their organoids also responded. These models may prove extremely useful for dictating therapy and predicting response and may become as useful in the future as cell lines in a basic research setting.

Although cell lines, PDXs, and PDOs have their advantages, these models still cannot fully replicate human disease. They do not allow natural tumor initiation or progression in the correct in situ microenvironment nor are they heterogeneous like most human tumors. Importantly, they do not model a normal immune environment. To overcome these shortfalls, transgenic models have been developed. A number of genetically engineered mouse models (GEMM) have been shown to give rise to ER+ disease. These include ESR1 (estrogen receptor) [7], cyclin D1 [8, 9], Wnt1 (Wnt family member 1) [10], p53 (tumor protein p53) [11], Stat1 (signal transducer and activator of transcription 1) [12], TGF $\alpha$ (transforming growth factor alpha) [13], AIB1 (amplified in breast cancer 1) [14, 15], Espl1 (extra spindle pole bodies like 1) [16], PIK3CA (phosphatidylinositol-4,5-bisphosphate 3kinase catalytic subunit alpha) [17], and PyMT (polyoma middle T oncoprotein) $[18,19]$. Crucial to modeling ER+ disease in GEMMs is to demonstrate reliance on E2 for growth and response to endocrine agents. However, only a few of these models demonstrate the expected hormonal responses. In Wnt1 transgenic mice that generated ER+ disease, tumors were refractory to both ovariectomy and tamoxifen treatment [10]. Similarity, tumors from ER $\alpha$ and cyclin D1 expressing transgenic mice developed despite tamoxifen treatment, suggesting inherent resistance [8]. Therefore, many of these models cannot lay claim to modeling ER+ breast cancer fully. Lack of response may be due to fast progression of these models to more aggressive phenotypes. For example in the PyMT model, ER+ tumors quickly lose expression and gain HER2 and cyclin D1 expression as tumors become more aggressive and metastatic [18]. Similarly, ER+ tumors in AIB1 transgenic mice have been shown to initially respond to tamoxifen treatment, but lose this response within days [20]. These studies indicate that early mouse mammary tumors may rely on estrogen activity; however, this is often lost, along with response to endocrine agents. Also, these studies highlight the need for further understanding and better models that do fully recapitulate human disease.

The lack of responsive ER+ models led us to fully characterize ER function in some of the available mouse cell lines of mammary cancer, with the goal of using these cells in a syngeneic immunocompetent model of ER+ disease. Our findings suggest that although many of these mouse cell lines do express ER, classical ER function and response to hormones and endocrine agents is lacking, most likely because ER is localized in the cytoplasm rather than nucleus. However, cytoplasmic ER appears to be functional and plays a role in promoting survival. This survival function requires NFKB activity since the combination of tamoxifen or other selective estrogen receptor modulators (SERMs) with NFKB inhibitors led to oxidative stress and apoptosis. Taken together, our findings suggest that mouse models of ER+ breast cancer fail to model human disease largely due to the lack of classical nuclear ER activity, but may be useful in understanding extranuclear functions of ER.

\section{Materials and Methods}

Reagents $17 \beta$-estradiol (E2), 4-hydroxy-tamoxifen (4OHT), Fulvestrant (ICI 182,780, referred to throughout as ICI), dimethyl fumarate (DMF), Raloxifene (RAL), and propidium iodide (PI) were purchased from Sigma. IKK7 was purchased from Selleck Chemicals. The antibodies for ER $\alpha$ (\#8644) and TBP (\#8515) were purchased from Cell Signaling. The antibody for GAPDH (10494-1-AP) was purchased from Proteintech. The anti-rabbit Alexa Fluor 488 antibody (ab150073) was purchased from Abcam. Goat anti-rabbit HRP-conjugated secondary antibody (\#31460) was purchased from Invitrogen.

Cell Culture Mouse mammary cancer cell lines used in this study are detailed in Table 1 . J110 cells were maintained in DMEM/F12 media and Py2T, E0771, 4T1, and Met1 were maintained in DMEM $(1 \times)$ containing $4.5 \mathrm{~g} / \mathrm{L}$ D-glucose, Lglutamine, and $25 \mathrm{mM}$ HEPES. All media contained phenol 
Table 1 Mouse mammary cancer cell lines

\begin{tabular}{lllll}
\hline Cell line & Tumor origin & Description & Original Source & Published ER $\alpha$ Status \\
\hline J110 & GEMM & Derived from FVB-MMTV-AIB1 mouse tumor & $\begin{array}{c}\text { Myles Brown; Dana-Farber Cancer Institute, } \\
\text { Cambridge, USA [21] }\end{array}$ & $+[15]$ \\
Py2T & GEMM & Derived from FVB-MMTV-PyMT mouse tumor & $\begin{array}{c}\text { Gerhard Christofori; Institute of Biochemistry } \\
\text { and Genetics, Basel, Switzerland [19] }\end{array}$ & $+[19]$ \\
E0771 & Spontaneous & Derived from a C57BL/6J mouse tumor & $\begin{array}{c}\text { Sugiura K; Sloan-Kettering Institute, New } \\
\text { York., USA [22] }\end{array}$ & $+($ cyto) [23], \\
4T1 & Spontaneous & Derived from BALB/cfC3H mouse tumor & $\begin{array}{c}\text { Miller FR; Brown University, Providence, } \\
\text { Rhode Island, USA [26] }\end{array}$ & $-[25,27]$ \\
Met-1 (fvb2) & GEMM & Derived from FVB/N-Tg(MMTV-PymT) mouse & $\begin{array}{c}\text { Guy CT, McMaster University, Ontario, } \\
\text { Canada [28] }\end{array}$ & $-[25,29]$
\end{tabular}

red and 5\% FBS and was therefore considered "estrogenized", as well as $1 \%$ penicillin-streptomycin antibiotics. Before treatment with E2, cells were cultured in phenol red free media supplemented with 5\% charcoal-dextran stripped FBS (steroid depleted media) and $1 \%$ penicillin-streptomycin antibiotics for 3 days.

RNA Extraction and RT-qPCR Total RNA was isolated using TRIzol reagent (Invitrogen) according to the manufacturer's instructions. A total of $0.5 \mu \mathrm{g}$ of RNA was used to generate cDNA at a total volume of $10 \mu \mathrm{l}$, using M-MLV Reverse Transcriptase reagents with the addition of 50 pmol random hexamer, and $1 \mathrm{mM}$ deoxy-NTP per reaction (all Invitrogen). cDNA was diluted to a total volume of $100 \mu$ with sterile $\mathrm{ddH}_{2} \mathrm{O}$. qPCR was performed using $2 \mu$ of diluted cDNA, $1 \times$ SYBR Green PCR Master Mix (Applied Biosystems), and $125 \mathrm{nM}$ forward and reverse primer (sequences available on request). Reactions were carried out on an ABI StepOne Real-time PCR system (Applied Biosystems) under the following conditions: $10 \mathrm{~min}$ at $95 \mathrm{C}$ followed by 40 cycles of $95 \mathrm{C}$ for $15 \mathrm{~s}$ then $60 \mathrm{C}$ for $1 \mathrm{~min}$. The fold change in expression of each gene was calculated using the $\Delta \Delta \mathrm{Ct}$ method, with GAPDH as an internal control.

Protein Extraction and Western Blot Whole cell lysates were prepared using the M-PER reagent, and cytoplasmic and nuclear lysates were prepared using the NE-PER kit (Thermo Scientific), according to the manufacturer's protocol. Proteins were separated by SDS-PAGE (Bio-Rad Laboratories), transferred to nitrocellulose membranes (Thermo Scientific), blocked for $1 \mathrm{~h}$ in $5 \%$ nonfat dry milk (Lab Scientific) in $1 \times$ TBS-T, and incubated overnight with primary antibody. The following day, the membranes were rinsed with $1 \times$ TBS-T and incubated with horseradish peroxidase-conjugated secondary antibody for $1 \mathrm{~h}$. Pierce Supersignal West Pico plus chemiluminescent substrate (Thermo Scientific) was applied to the membranes and the signal was visualized on a Molecular Imager ChemidocXRS (Bio-Rad Laboratories). Images were processed using Quantity One software (Bio-Rad Laboratories).
Cell Proliferation Cell confluency was determined using the Celigo Imaging Cytometer (Nexcelom Bioscience). DNA content was determined using Hoechst 33342 dye (Life Technologies). Fluorescence was read using Synergy HT microplate reader (BioTek). Cell numbers were extrapolated from standard curves.

Syngeneic Tumor Study Mouse experiments were carried out at the animal facility at the University of Illinois at Chicago in accordance with the institutional guidelines and procedures, with approval from the Institutional Animal Care and Use Committee. FVB/N mice at 4 weeks of age were purchased from Taconic. A total of $1000 \mathrm{~J} 110$ cells were orthotopically injected into both left and right thoracic mammary fat pads and allowed to form tumors of $0.2 \mathrm{~cm}^{2}$ in area. Animals were then randomized into four groups and treated daily ( 5 days/week) as follows: vehicle control, tamoxifen $(100 \mu \mathrm{g}$ in corn oil, by intraperitoneal injection), DMF (30 mg/ $\mathrm{kg}$ in $0.8 \%$ methyl cellulose, by oral gavage), or the combination of tamoxifen and DMF. Tumor size was measured using an electronic caliper and volume $\left(\mathrm{V}=\left(\right.\right.$ length $\times$ width $\left.\left.^{2} \times \pi\right) / 2\right)$ calculated.

Immunofluorescence Cells were seeded onto glass coverslips and allowed to attach. Cells were fixed with $4 \%$ paraformaldehyde for $10 \mathrm{~min}$ followed by permeabilization with $0.2 \%$ triton X-100, blocking with casein, and then incubation with the primary ER $\alpha$ antibody for $1 \mathrm{~h}$. After washing with TBS, cells were incubated with the secondary Alexa Fluor 488 antibody and further washed with TBS. Coverslips were mounted onto glass slides with ProLong ${ }^{\text {TM }}$ Gold Antifade Mountant with DAPI reagent (Life Technologies). Images were acquired on a Leica DMi8 microscope at $63 \times$ magnification. J110, Py2T, and Met1 images were acquired using the same microscope settings. MCF-7 cells, which served as a positive control, were imaged with reduced exposure in the FITC channel due to high expression of $\mathrm{ER} \alpha$.

$\mathrm{H}_{2} \mathrm{O}_{2}$ Assay $\mathrm{H}_{2} \mathrm{O}_{2}$ was measured using ROS-Glo ${ }^{\text {TM }} \mathrm{H}_{2} \mathrm{O}_{2}$ Assay (Promega) in accordance with the manufacturer's 
instructions. Luminescence was read on a Synergy HT microplate reader (BioTek). Cells were then counterstained with Hoechst 33342 dye for $30 \mathrm{~min}$, and the fluorescence reading taken, which was used to normalize $\mathrm{H}_{2} \mathrm{O}_{2}$ values for cell number.

ATP Assay ATP was extracted from treated cells using the method described by Yang et al. [30], with some modifications. Briefly, cell pellets were re-suspended in $500 \mu \mathrm{l}$ of boiling $\mathrm{ddH}_{2} \mathrm{O}$ and heated at $100 \mathrm{C}$ for $10 \mathrm{~min}$, vortexing frequently. Samples were centrifuged at $1500 \times g$ and supernatant removed and put on ice. The concentration of ATP was quantified using the ATP determination kit (Invitrogen), as per the manufacturer's protocol and the concentration of ATP in each sample was determined using a standard curve.

Cell Death Assays Cell viability was measured using $1 \mu \mathrm{g} / \mathrm{ml}$ PI to stain dead/dying cells along with Hoechst 33342 dye to stain all cells for $30 \mathrm{~min}$. Total and dead cells were detected using the Celigo Imaging Cytometer (Nexcelom Bioscience), and percentage of total cells stained with PI calculated. To assess apoptosis, levels of activated caspase 3/7 were measured. Briefly, cells were washed with PBS and then incubated for $30 \mathrm{~min}$ at $37 \mathrm{C}$ with Hoechst 33342 dye and CellEvent Caspase-3/7 Green Detection Reagent (Invitrogen). The number of cells with positive green fluorescent signal was measured in the green fluorescence channel and the total number of cells was counted in blue fluorescence channel, both using Celigo's colony count application. The percentage of apoptotic cells was calculated as the number of cells with positive green fluorescent signal over the total number of cells per well.

Statistical Analysis Data are presented as mean \pm SD or SEM of two or more biological replicates, representative of two or more experimental replicates. Statistical analysis was performed using GraphPad 8 software using linear regression analysis or one-way/two-way ANOVA (followed by Dunnett's/Tukey posttest), as appropriate.

\section{Results}

\section{ERa Is Expressed but Lacks Classical Activity in a Panel of Mouse Mammary Cancer Cell Lines}

A panel of cell lines generated from mouse mammary tumors (see Table 1 for details), many of which have been reported to be ER $\alpha$ positive in the literature, were assessed for the presence of ER $\alpha$. We found that J110, Py2T, E0771, and 4T1 cells expressed ER $\alpha$ mRNA and protein, albeit at a lower level than in mouse uterus and MCF-7 cells (Fig. 1). The majority of uterine ER protein was around 55-60 KDa in size, possibly representing a truncated/modified form of the protein, whereas the mammary cell lines expressed $66 \mathrm{kDa} \mathrm{ER} \alpha$, which was similar in size to that seen in MCF-7 cells. In contrast, Met1 cells, which are widely considered to be ER $\alpha$ negative [25, 29], showed minimal ER $\alpha$ mRNA and undetectable ER $\alpha$ protein. It is important to note that $\mathrm{ER} \beta$ mRNA was not detected in any of the mouse cell lines (data not shown).

We next examined ER $\alpha$ activity based on hormonedependent proliferation and target gene expression in two of these cell lines: J110 and Py2T. In steroid-depleted culture media, we found that neither cell line proliferated in response to E2 (Fig. 2a). Furthermore, in estrogenized media, SERMs (4OHT and RAL) and a selective estrogen receptor degrader (SERD; ICI) had only a minimal effect on cell growth (Fig. $2 b$ ), indicating that cells may proliferate independently of ER ligand. To further characterize ER activity, we assessed a number of classical ER target genes based on the literature [31, 32]. We found that none of these genes were significantly regulated in response to E2 and/or 4OHT (Fig. 2c). This was true for up to $8 \mathrm{~h}$ of treatment, where still no response was observed (data not shown). The lack of ER transcriptional activity or ligand-dependent proliferation indicates that neither cell line exhibits classical ER function.

\section{The Combination of ER and NFKB Inhibitors Suppress J110 and Py2T Cell and Tumor Growth}

As J110 and Py2T express ER but had little response to ER ligands, we postulated that these cells could represent models
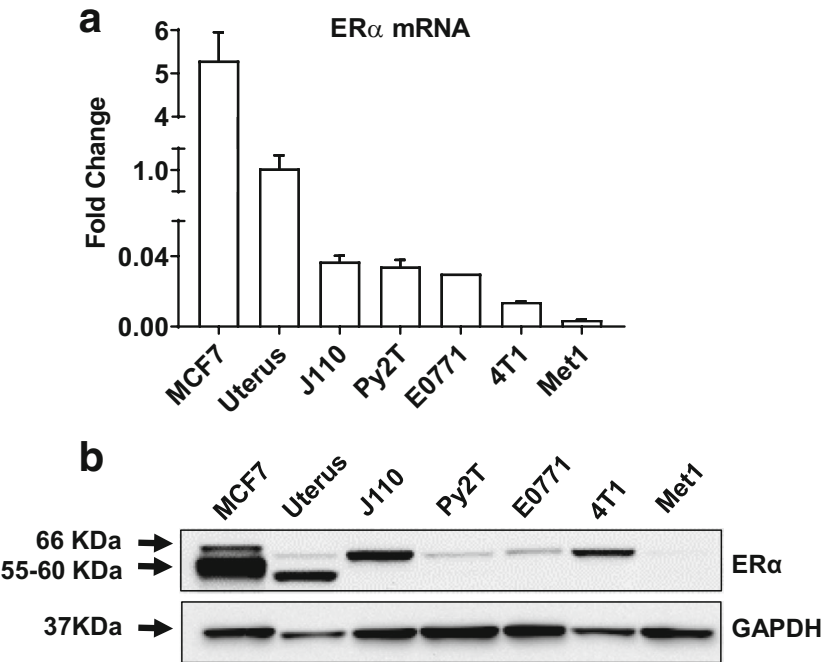

Fig. 1 Estrogen receptor $\alpha$ is expressed in mouse mammary cancer cell lines. a ER $\alpha$ mRNA levels were assessed by qPCR in mouse cell lines J110, Py2T, E0771, 4T1, and Met1, and normalized to GAPDH. Fold change relative to $\mathrm{ER} \alpha$ in mouse uterine tissue (positive control) is indicated. MCF-7 cells served as a positive human control. b Whole cell extracts from J110, Py2T, E0771, 4T1, and Met1, along with mouse uterine tissue and MCF-7 cells (positive controls), were assessed for $\mathrm{ER} \alpha$ protein expression by Western blot. Five times less uterine and MCF-7 protein was loaded compared to mouse cell lines. GAPDH was used as a loading control 

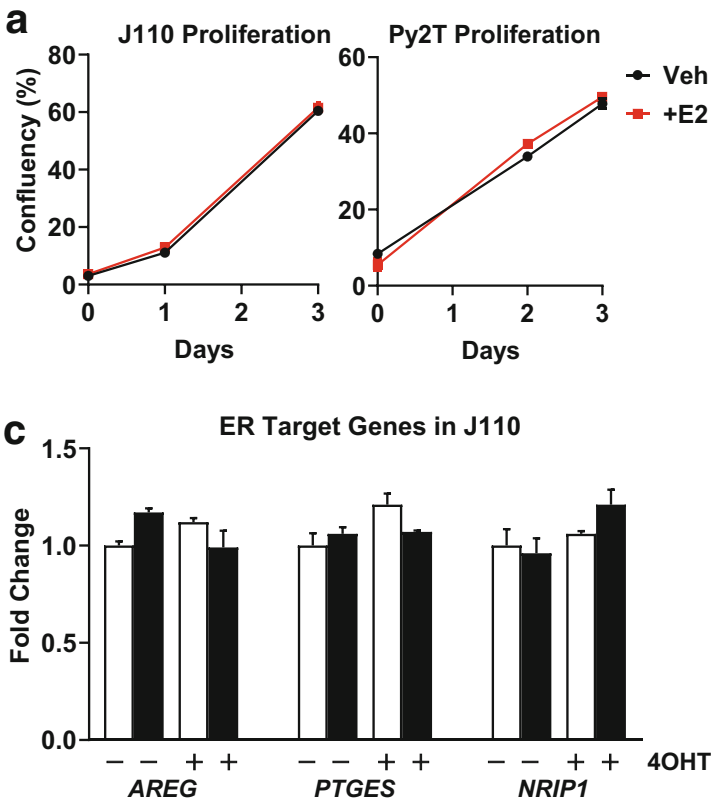

Fig. 2 J110 and Py2T cells do not respond to ER ligands. a J110 and Py2T cells were cultured in steroid-depleted media and treated for 3 days with E2 $(10 \mathrm{nM})$ or vehicle (Veh, $0.001 \% \mathrm{EtOH})$. Cell confluency measured using a Nexcelom Celigo Imaging Cytometer. b J110 and Py2T cells were cultured in estrogenized media and then treated with 4OHT $(1 \mu \mathrm{M})$, ICI $(1 \mu \mathrm{M})$, or Ral $(1 \mu \mathrm{M})$ for 3 days. Cell confluency measured

of endocrine therapy-resistant breast cancer. In patients with $\mathrm{ER}+$ breast cancer, endocrine therapy resistance develops, in part, due to activation of other signaling pathways such as MAPK, AKT, EGFR/HER2 [33-35]. Therefore, inhibitors to several of these pathways were tested. Few of the inhibitors suppressed cell growth alone. However, in combination with 4OHT, several were found to significantly suppress cell growth (Supplemental Fig. 1).

Of particular note, two NFKB inhibitors IKK7 and DMF, in combination with 4OHT, suppressed growth cells to the greatest extent. IKK7 is an inhibitor of IKK $\alpha / \beta$, a key complex in the NF $\kappa B$ signaling pathway [36, 37]. DMF covalently modifies the NFKB transcription factor p65 and blocks its nuclear translocation and DNA binding ability, thus suppressing NFKB transcriptional activity [38]. As shown in Fig. 3, the combination of NFKB inhibitors with either SERMs or a SERD resulted in a significant suppression of cell growth, compared to either compound alone, except DMF and ICI, which showed a similar trend but did not reach significance. In contrast, the ER-negative Met1 cell line showed no further suppression of growth with combination treatment compared to the NFkB inhibitor alone (Supplemental Fig. 2).

To explore whether combination therapy targeting ER and $\mathrm{NF} \kappa \mathrm{B}$ would inhibit tumor growth in vivo, J110 cells were injected into the mammary fat pad of immunocompetent FVB/Ntac mice and syngeneic tumors were allowed to form. After initiation of the primary tumor, tamoxifen, DMF, or both were administered to mice and tumor volume observed over
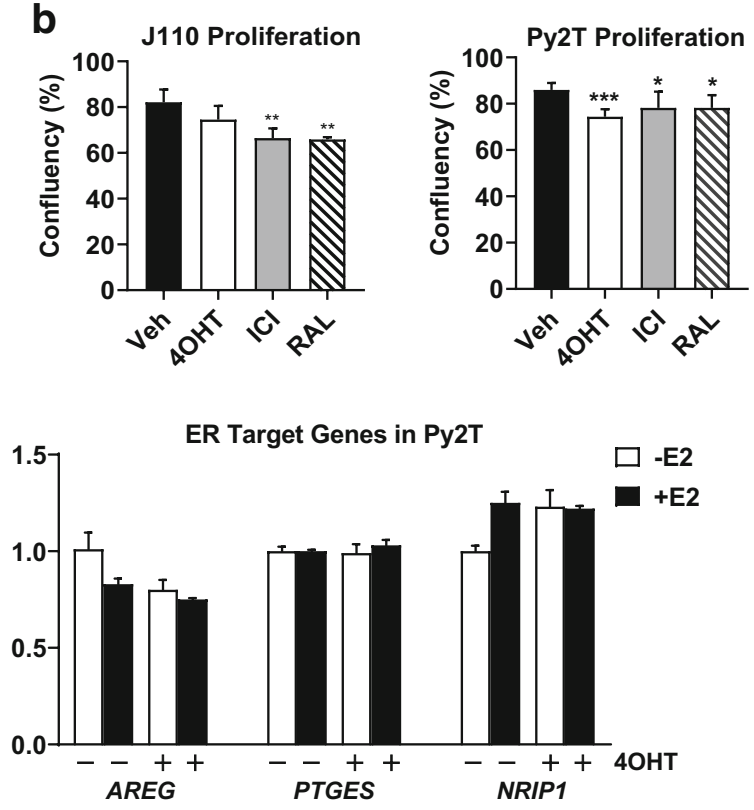

using a Nexcelom Celigo Imaging Cytometer. c Cells were pretreated with vehicle or $4 \mathrm{OHT}$ for $2 \mathrm{~h}$, and then, vehicle or E2 was added for an additional $2 \mathrm{~h}$. RNA was extracted and qPCR was performed for the ER target genes AREG, PTGES, and NRIP1. Fold change for each gene was calculated relative to vehicle control. $* P<0.05 ; * * P<0.01$; $* * * P<0.001$ relative to vehicle treatment

time. By the end of the study, only the combination treatment resulted in a significant reduction in tumor size and weight compared to tumors in untreated mice (Fig. 4). Together, these data indicate that co-inhibition of NFKB and ER pathways results in a tumor suppressive response in mouse cell lines and tumors that are unresponsive to endocrine agents alone.

\section{Cytoplasmic ER and NFKB Protect Cells from Oxidative Stress and Apoptosis}

Our results thus far suggest that activation of NFKB may be a contributing factor in suppressing classical ER activity, which has been previously described in the literature [39-41]. There is some evidence that inhibition of NFKB in endocrineresistant cells restores ER activity, resulting in cells that are responsive to endocrine agents $[42,43]$. Therefore, we tested whether combination therapy with ER and NFKB inhibitory agents affected ER's transcriptional function. However, neither IKK 7 nor DMF alone or in combination with 4OHT had any effect on the expression of the ER target gene AREG, whereas the combination caused a minimal increase in PTGES expression (Fig. 5a). This increase was unexpected given that we have previously shown that ER and NFKB stimulate PTGES expression [44]. We also examined whether $\mathrm{NF} K \mathrm{~B}$ inhibitors affected ER expression or localization. Surprisingly, ER was exclusively cytoplasmic, regardless of treatment (Fig. 5b). ER localization was also confirmed by immunofluorescence where ER exhibited a distinct punctate 
Fig. 3 The combination of ER and NFKB inhibitors reduced $\mathrm{J} 110$ and Py2T cell number in vitro. Cells were cultured in estrogenized media and then treated with a $4 \mathrm{OHT}(1 \mu \mathrm{M}), \mathbf{b}$ ICI $(1 \mu \mathrm{M})$, or $\mathbf{c} \operatorname{Ral}(1 \mu \mathrm{M})$ in the presence of IKK7 $(1 \mu \mathrm{M}$, left panels) or DMF $(30 \mu \mathrm{M}$, right panels) for $48 \mathrm{~h}$. DNA was quantified as an indication of cell number using Hoechst 33342 dye. ns, not significant, $* P<0.05$; $* * P<0.01 ; * * * P<0.001$ relative to IKK7 or DMF treatment alone
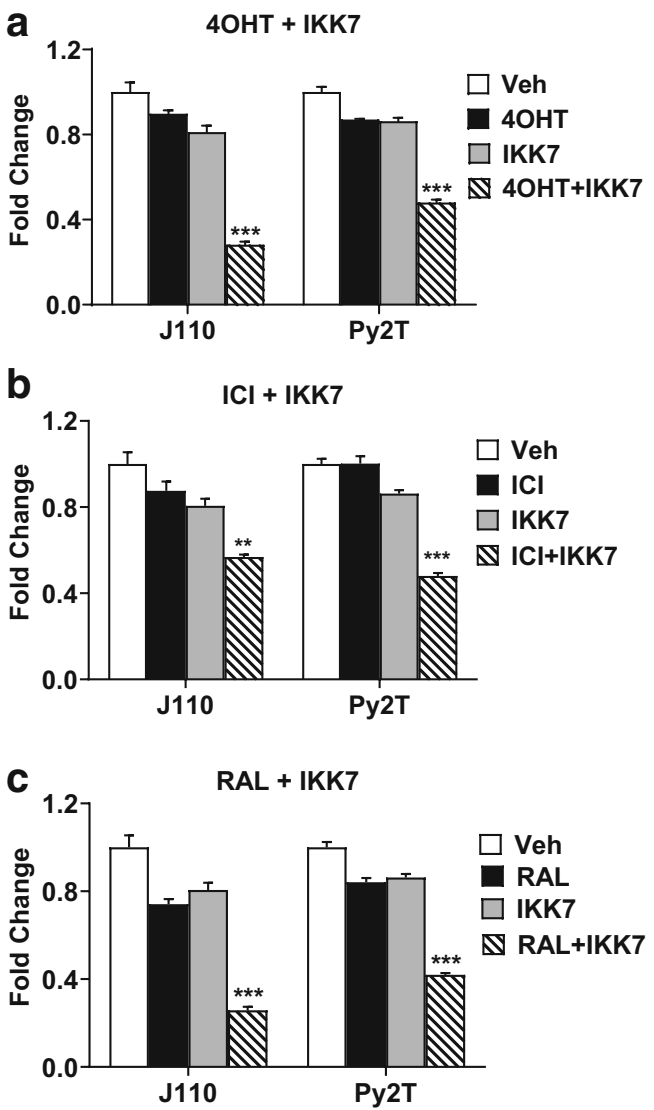
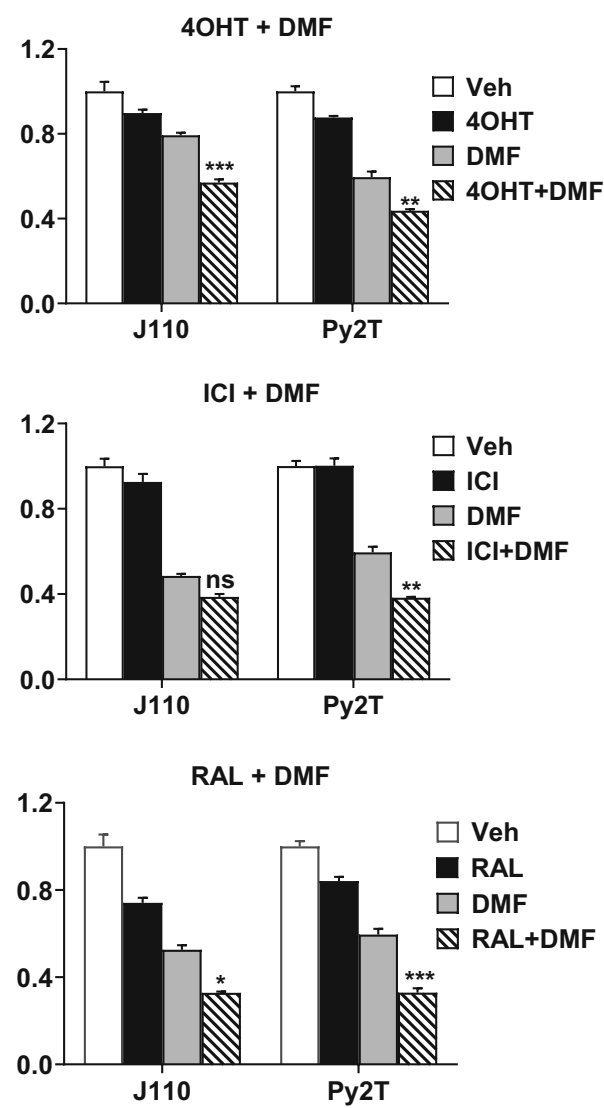

staining pattern in the cytoplasm (Fig. 5c, Supplemental Fig. 3). This was in contrast to MCF-7 cells, which display typical nuclear ER localization, and Met1 cells, which lack ER altogether (Supplemental Fig. 3). Together, these data suggest that restoration of ER's transcriptional activity does not occur upon NFKB inhibition, as it is not localized to the nucleus. Moreover, the cytoplasmic location of ER in these cells may suggest alternative extra-nuclear mechanisms contributing to growth suppression observed with ER and NFKB inhibition.

Previous work from the Levin group demonstrated that extra-nuclear ER was associated with protection from oxidative stress, and subsequent apoptosis, by reprogramming their cell metabolism [45]. Other studies have confirmed a protective role for extra-nuclear ER, specifically in ischemic heart injury [46], by attenuating oxidative stress. Likewise, NFKB is a well-established inhibitor of oxidative stress [47, 48]. We therefore investigated oxidative damage as a mechanism for the growth suppressive effects we observed in ER+ mouse cell lines following ER and NFKB inhibition. Indeed, we found an increase in $\mathrm{H}_{2} \mathrm{O}_{2}$ production upon $\mathrm{ER}$ and $\mathrm{NF} \kappa \mathrm{B}$ co-inhibition, indicative of oxidative stress, compared to the NFkB inhibitors alone (Fig. 6a). This finding was further
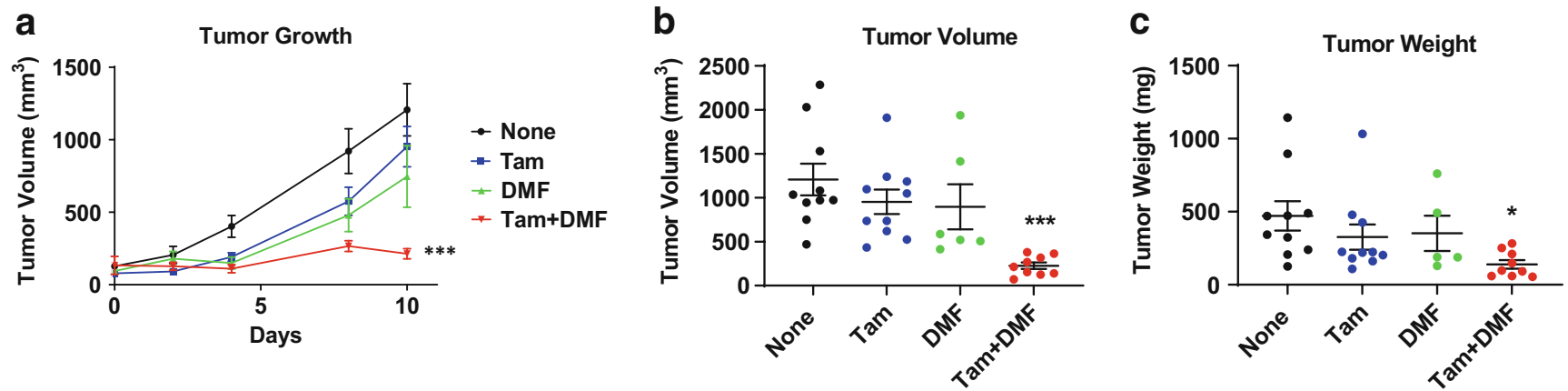

Fig. 4 The combination of ER and NFKB inhibitors reduced J110 tumor growth in vivo. J110 cells were injected into mammary fat pads of FVB/ Ntac mice. Once tumors reached $0.2 \mathrm{~mm}^{2}$, vehicle, tamoxifen $(100 \mu \mathrm{g} /$ mouse), DMF (30 mg/kg), or both were administered daily for 10 days. a

Tumor volume was measured every 2 days and plotted over time. b, c Final tumor volume and tumor wet weight were measured post-mortem. $* P<0.05 ; * * * P<0.001$ relative to none 
Fig. 5 Inhibition of ER and NFKB does not alter ER's transcriptional function nor cytoplasmic localization. J110 cells were treated with vehicle or 4OHT $(1 \mu \mathrm{M})$ in the presence or absence of IKK7 $(1 \mu \mathrm{M})$ or DMF $(30 \mu \mathrm{M})$ for $48 \mathrm{~h}$. a RNA was extracted and mRNA levels of the ER target genes PTGES and AREG were assessed. b Nuclear and cytoplasmic protein fractions from J110 cells were assessed for ER protein level Western blot. TBP was used as a nuclear and GAPDH as a cytoplasmic loading control. c ER $\alpha$ protein localization (green) in J110 cells was assessed using immunofluorescence. Punctate extra-nuclear staining indicated by white arrows. Cell nuclei were counterstained with DAPI (blue). $* P=$ $<0.05, * * P<0.01$ relative to IKK7 or DMF treatment alone a

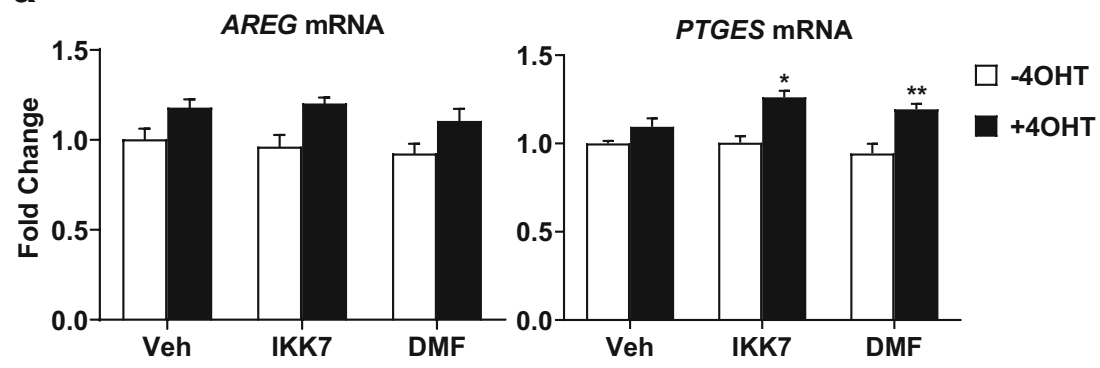

b

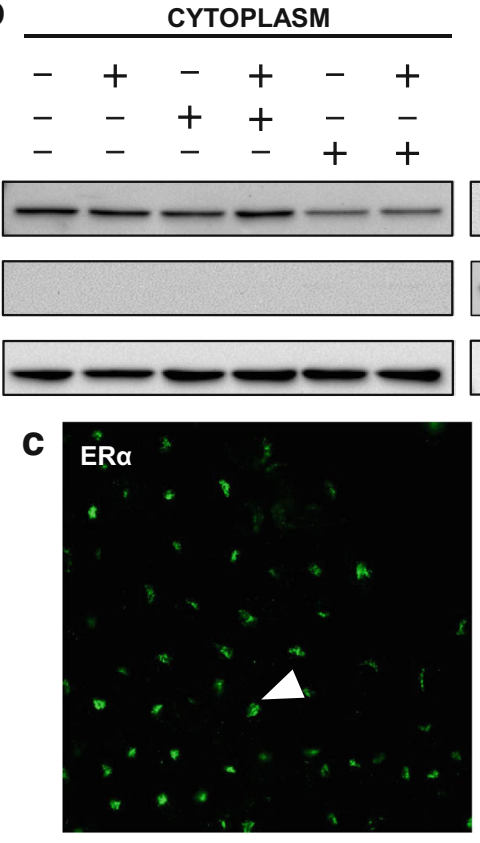

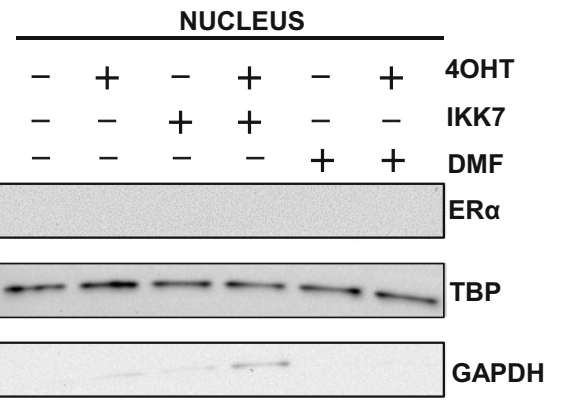

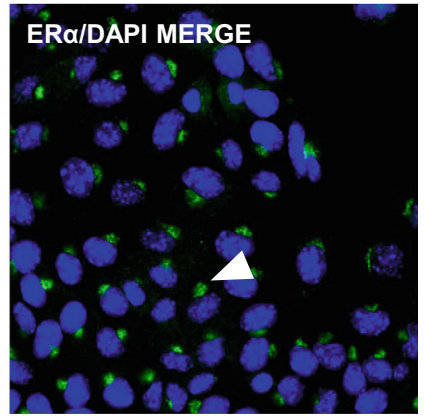

supported by the upregulation of oxidative stress-associated genes, HMOX1, NRF2, and GPX1, with combination treatment (Fig. 6b). Moreover, when cells undergo oxidative stress, the levels of ATP in the cell are significantly attenuated [49] and apoptosis can occur [50]. We observed both significantly reduced ATP and increased cell death/apoptosis in J110 cells co-treated with ER and $\mathrm{NF} \kappa \mathrm{B}$ inhibitors compared to IKK7 or DMF alone (Fig. 6c-e). As mitochondrial ER has been associated with oxidative stress by others [51-53], we investigated whether cytoplasmic ER is localized to the mitochondria. However, ER and mitochondrial staining patterns were distinctly different, suggesting no colocalization (Supplemental Fig. 4). These data suggest that cytoplasmic but not mitochondrial ER, in addition to $\mathrm{NF}_{\kappa} \mathrm{B}$, protect mouse mammary cancer cells against oxidative stress.

\section{Discussion}

We observed ER expression in multiple mouse mammary cancer cell lines, derived from either GEMM or spontaneous tumor models, and yet these cells were unresponsive to E2 and only minimally responsive to SERMs or SERDs. Interestingly, ER was found to be predominantly localized to the cytoplasm. Despite an apparent lack of classical nuclear activity, ER still appeared to be functionally important as coinhibition of ER and NF $\kappa$ B resulted in an increase in apoptosis and oxidative damage. Thus, this study provides new insights into why many ER+ mouse mammary cancer models lack E2dependence and response to tamoxifen that is typically observed in human ER+ breast tumors and cell lines.

One hypothesis suggested by our findings is that the cytoplasmic localization of ER may be a consequence of disease progression. Tumors that form in AIB1 mice are reported to be $\mathrm{ER}+$ and tumor formation is reliant on ER, as ovariectomy prevented the development of invasive mammary tumors. However, once developed, they subsequently lose their response to estrogen [21]. In ovariectomized mice, injection of cells derived from AIB1 tumors resulted in a similar growth rate compared to untreated mice. However, it was interesting that the ovariectomized mice had fewer metastasis, suggesting that despite their lack of response, E2 may provide protection from tumor progression [21]. Another study, also using cells derived from the AIB1 transgenic model, showed that tumors 

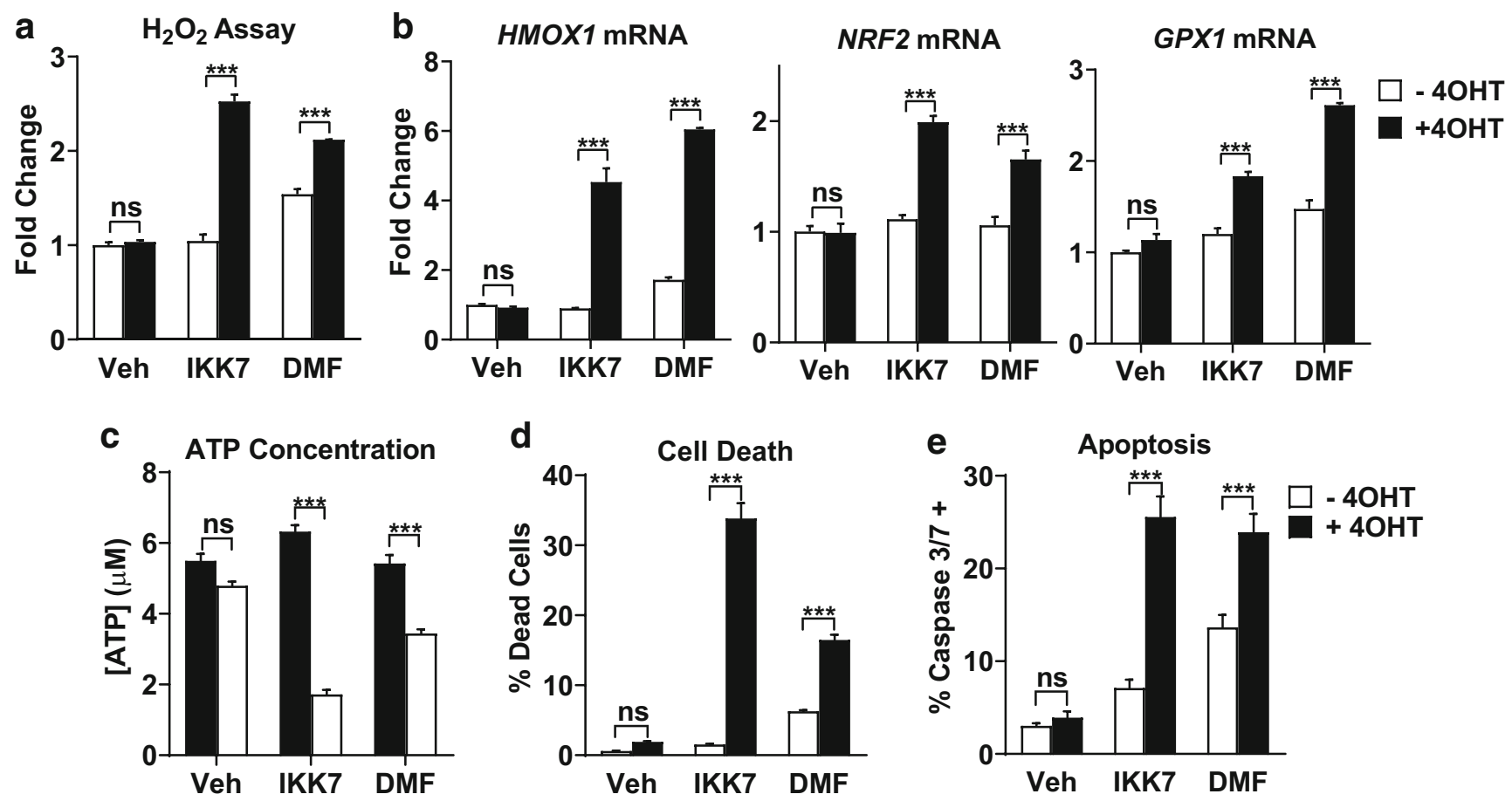

Fig. 6 The combination of ER and NFKB inhibitors promoted cell death via an increase in oxidative stress apoptosis. J110 cells were treated with vehicle $(0.001 \% \mathrm{EtOH})$ or $4 \mathrm{OHT}(1 \mu \mathrm{M})$ in the presence or absence of IKK7 $(1 \mu \mathrm{M})$ or DMF $(30 \mu \mathrm{M})$ for $48 \mathrm{~h}$. a Oxidative stress was measured by quantification of $\mathrm{H}_{2} \mathrm{O}_{2}$ levels in cells after treatments. Fold change for each treatment is indicated relative to vehicle. $\mathbf{b}$ RNA was extracted and qPCR performed to assess mRNA levels of the oxidative stressassociated genes HMOX1, NRF2, and GPX1. c ATP concentration

initially responded to tamoxifen in vivo but stopped responding over time, and no difference in size between control and tamoxifen-treated tumors was observed at the end of the study [20]. Similarly, ER+ tumors arising from the PyMT models express ER early on but this is lost as tumors progress. These tumors appear to be estrogen-independent since ovariectomized mice or tamoxifen-treated mice still developed mammary tumors [54]. Cell lines derived from this model express ER but also express the basal keratin KRT14, suggesting that progression and transformation to a more aggressive phenotype may have begun [55]. Loss of ligand response has also been observed the mouse mammary cancer cell line E0771, originally from a spontaneous mammary tumor in a female C57BL/6 mouse [23]. Not only were the cells minimally responsive to tamoxifen in vivo and unresponsive in vitro, they also displayed diffuse cytoplasmic ER staining patterns. Clearly, loss of ER activity in ER+ mouse models is common and progression to this state is rapid. Thus, it is possible that cytoplasmic ER and lack of response in J110 and Py2T cells may result from disease progression to an ER-independent state.

Several studies have described interacting partners of ER that can drive its cytoplasmic location and subsequent extranuclear role. For example, the proto-oncogene tyrosine-protein $(\mu \mathrm{M})$ was measured in cells after treatments. $\mathbf{d}$ The percentage of dead cells was measured using propidium iodide stain to stain dead cells and DAPI to stain all cells. e Activated caspase 3/7, as an indication of apoptosis, was measured using a CellEvent ${ }^{\mathrm{TM}}$ Caspase-3/7 Green Detection Reagent. The percentage of apoptotic (green) cells is indicated for each treatment condition. ns $=$ not significant, $* * * P<0.001$, relative to IKK7 or DMF treatment alone

kinase Src is the most widely studied ER interacting protein that is responsible for sequestering ER in the cytoplasm, and its inhibition has been shown to increase nuclear shuttling of ER [56-58]. The protein PELP1 (proline, glutamate and leucinerich protein 1) can act as a scaffolding protein between ER and Src and aids sequestration of ER in the cytoplasm [57, 59]. Similarly, MEMO (mediator of ERBB2-driven cell motility) can also enhance interaction between Src and ER, resulting in cytoplasmic retention, by inhibiting nuclear transport of this complex [60]. In addition, MTA1 (metastasis-associated 1) has the ability to sequester ER to the cytoplasm due to its ER binding motif [61]. Finally, methylation of ER by PRMT1 (protein arginine $\mathrm{N}$-methyltransferase 1) at R260 can promote cytoplasmic location of ER [62]. Whether any of these mechanisms may explain why ER is sequestered in the cytoplasm of mouse cell lines remains to be investigated.

Although nuclear ER has been well studied to promote cell survival through suppression of apoptotic genes or upregulation of anti-apoptotic genes, e.g., BCL-2 [63], several studies suggest that cytoplasmic ER is also linked to survival through various signaling pathways, such as PI3K/AKT [59], ERK1/2 [64], and MAPK [57, 65], as well as oxidative stress. For example, in ischemic neuronal injury, ER was found to protect against oxidative damage by attenuating NADPH oxidase 
activation and superoxide production [66]. Another study found that extra-nuclear ER was able to mediate protection from cardiac ischemia-reperfusion in mice, due to an increase in myocardial protein S-nitrosylation, which protects from oxidative stress [67]. Extra-nuclear ER has been shown to protect from apoptosis in pancreatic $\beta$-cells. In these cells, ER is predominantly cytoplasmic, and after acute $\mathrm{H}_{2} \mathrm{O}_{2}$ exposure to mimic oxidative injury, stimulation of ER by E2 protected cells from apoptosis [68]. These studies provide compelling evidence of a role for extra-nuclear ER in cellular protection against oxidative stress and may be applicable to the mouse mammary cancer models used in these studies.

It is interesting to ask if cytoplasmic ER promotes survival, then why do not SERMs or SERDs have discernable effects on J110 and Py2T cell survival? The finding that co-inhibition of ER and NFKB resulted in a significant increase in oxidative damage, apoptosis, and cell death is suggestive of a synthetic lethality paradigm. Synthetic lethality is a type of genetic interaction where suppression of two genes results in cell death whereas suppression of either one alone leaves cells viable $[69,70]$. This concept can also be applied to suppression of proteins or pathways. It is hypothesized that synthetically lethal interactions occur because redundant mechanisms are in place to maintain homeostasis when cells are subjected to various deficiencies, such as environmental, genetic, or mutational [71]. In the case of J110 and Py2T cells, when ER and $\mathrm{NF} \kappa \mathrm{B}$, two pro-survival pathways, are inhibited by chemical compounds, we observe oxidative damage leading to increased cell death, suggesting a compensatory or buffering relationship between ER and NFKB. This relationship could be the result of "between-pathway" or "within-pathway" interactions [72], either of which could be possible as ER and NFKB crosstalk has been addressed heavily in the literature [41]. Although this work has predominantly described transcriptional crosstalk, cytoplasmic crosstalk can also occur. For example, activation of PI3K, which is mediated by extranuclear ER, results in sequestration of NFKB in the cytoplasm [73]. Therefore, the survival mechanisms in J110 and Py2T cells may involve a complex convergence and compensatory function between cytoplasmic ER and NFKB.

Of utmost importance is whether the cytoplasmic function of ER and redundancy with the NFKB pathway is relevant to human disease. Although activation of NFKB is observed clinically during tumor progression and has been linked to endocrine resistance [39, 40, 43, 74, 75], cytoplasmic ER is less well described. One study by Welsh et al. assessed ER expression in nearly 3200 patient cases and found the average incidence of cytoplasmic ER was around 1.5\% [76]. However, this study examined ER expression in primary tumors. We hypothesize the context in which cytoplasmic ER may be more applicable is in advanced disease, e.g., having progressed on or after therapy. These samples may be less well represented in studies of cytoplasmic ER due to difficulty in obtaining samples after therapeutic failure or progression to aggressive disease. Taken together, our studies suggest that analysis of ER localization as a consequence of disease progression may represent a promising new direction to develop novel therapeutic strategies.

Acknowledgments We would like to thank Jermya Buckley for manuscript preparation. We would also like to thank Irida Kastrati, Oleksii Dubrovskyi, and Chirag Gopinath for technical assistance.

Funding Information This work was supported by the National Institutes of Health R01 CA-200669 (to JF).

\section{Compliance with Ethical Standards}

Conflict of Interest The authors declare that they have no conflicts of interest.

\section{References}

1. Fisher B, Redmond C, Fisher ER, Caplan R (1988) Relative worth of estrogen or progesterone receptor and pathologic characteristics of differentiation as indicators of prognosis in node negative breast cancer patients: findings from National Surgical Adjuvant Breast and bowel project protocol B-06. J Clin Oncol 6(7):1076-1087

2. Pan H, Gray R, Braybrooke J, Davies C, Taylor C, McGale P, Peto R, Pritchard KI, Bergh J, Dowsett M, Hayes DF, EBCTCG (2017) 20 -year risks of breast-cancer recurrence after stopping endocrine therapy at 5 years. N Engl J Med 377(19):1836-1846

3. Sflomos G, Dormoy V, Metsalu T, Jeitziner R, Battista L, Scabia V, Raffoul W, Delaloye JF, Treboux A, Fiche M, Vilo J, Ayyanan A, Brisken C (2016) A preclinical model for ERalpha-positive breast cancer points to the epithelial microenvironment as determinant of luminal phenotype and hormone response. Cancer Cell 29(3):407422

4. Pompili L, Porru M, Caruso C, Biroccio A, Leonetti C (2016) Patient-derived xenografts: a relevant preclinical model for drug development. J Exp Clin Cancer Res 35(1):189

5. Dobrolecki LE, Airhart SD, Alferez DG, Aparicio S, Behbod F, Bentires-Alj M, Brisken C, Bult CJ, Cai S, Clarke RB, Dowst H, Ellis MJ, Gonzalez-Suarez E, Iggo RD, Kabos P, Li S, Lindeman GJ, Marangoni E, McCoy A, Meric-Bernstam F, Piwnica-Worms H, Poupon MF, Reis-Filho J, Sartorius CA, Scabia V, Sflomos G, Tu Y, Vaillant F, Visvader JE, Welm A, Wicha MS, Lewis MT (2016) Patient-derived xenograft (PDX) models in basic and translational breast cancer research. Cancer Metastasis Rev 35(4):547573

6. Sachs N, de Ligt J, Kopper O, Gogola E, Bounova G, Weeber F et al (2018) A living biobank of breast cancer organoids captures disease heterogeneity. Cell 172(1-2):373-86.e10

7. Tilli MT, Frech MS, Steed ME, Hruska KS, Johnson MD, Flaws JA, Furth PA (2003) Introduction of estrogen receptor-alpha into the tTA/TAg conditional mouse model precipitates the development of estrogen-responsive mammary adenocarcinoma. Am J Pathol 163(5):1713-1719

8. Miermont AM, Cabrera MC, Frech SM, Nakles RE, Diaz-Cruz ES, Shiffert MT et al (2012) Association of over-expressed estrogen receptor alpha with development of tamoxifen resistant hyperplasia and adenocarcinomas in genetically engineered mice. Anat Physiol (Suppl 12) 
9. Lin DI, Lessie MD, Gladden AB, Bassing CH, Wagner KU, Diehl JA (2008) Disruption of cyclin D1 nuclear export and proteolysis accelerates mammary carcinogenesis. Oncogene. 27(9):1231-1242

10. Zhang X, Podsypanina K, Huang S, Mohsin SK, Chamness GC, Hatsell S et al (2005) Estrogen receptor positivity in mammary tumors of Wnt-1 transgenic mice is influenced by collaborating oncogenic mutations. Oncogene. 24(26):4220-4231

11. Medina D, Kittrell FS, Shepard A, Stephens LC, Jiang C, Lu J, Allred DC, McCarthy M, Ullrich RL (2002) Biological and genetic properties of the p53 null preneoplastic mammary epithelium. FASEB J 16(8):881-883

12. Chan SR, Vermi W, Luo J, Lucini L, Rickert C, Fowler AM, Lonardi S, Arthur C, Young LJ, Levy DE, Welch MJ, Cardiff RD, Schreiber RD (2012) STAT1-deficient mice spontaneously develop estrogen receptor alpha-positive luminal mammary carcinomas. Breast Cancer Res 14(1):R16

13. Rose-Hellekant TA, Schroeder MD, Brockman JL, Zhdankin O, Bolstad R, Chen KS, Gould MN, Schuler LA, Sandgren EP (2007) Estrogen receptor-positive mammary tumorigenesis in TGFalpha transgenic mice progresses with progesterone receptor loss. Oncogene. 26(36):5238-5246

14. Torres-Arzayus MI (2004) Font de Mora J, Yuan J, Vazquez F, Bronson $\mathrm{R}$, rue $\mathrm{M}$, et al. high tumor incidence and activation of the PI3K/AKT pathway in transgenic mice define AIB1 as an oncogene. Cancer Cell 6(3):263-274

15. Torres-Arzayus MI, Yuan J, DellaGatta JL, Lane H, Kung AL, Brown M (2006) Targeting the AIB1 oncogene through mammalian target of rapamycin inhibition in the mammary gland. Cancer Res 66(23):11381-11388

16. Mukherjee M, Ge G, Zhang N, Edwards DG, Sumazin P, Sharan SK, Rao PH, Medina D, Pati D (2014) MMTV-Espll transgenic mice develop aneuploid, estrogen receptor alpha (ERalpha)-positive mammary adenocarcinomas. Oncogene. 33(48):5511-5522

17. Adams JR, Xu K, Liu JC, Agamez NM, Loch AJ, Wong RG, Wang W, Wright KL, Lane TF, Zacksenhaus E, Egan SE (2011) Cooperation between Pik3ca and p53 mutations in mouse mammary tumor formation. Cancer Res 71(7):2706-2717

18. Lin EY, Jones JG, Li P, Zhu L, Whitney KD, Muller WJ et al (2003) Progression to malignancy in the polyoma middle T oncoprotein mouse breast cancer model provides a reliable model for human diseases. Am J Pathol 163(5):2113-2126

19. Waldmeier L, Meyer-Schaller N, Diepenbruck M, Christofori G (2012) Py2T murine breast cancer cells, a versatile model of TGFbeta-induced EMT in vitro and in vivo. PLoS One 7(11): e48651

20. Gattelli A, Nalvarte I, Boulay A, Roloff TC, Schreiber M, Carragher N, Macleod KK, Schlederer M, Lienhard S, Kenner L, Torres-Arzayus MI, Hynes NE (2013) Ret inhibition decreases growth and metastatic potential of estrogen receptor positive breast cancer cells. EMBO Mol Med 5(9):1335-1350

21. Torres-Arzayus MI, Zhao J, Bronson R, Brown M (2010) Estrogendependent and estrogen-independent mechanisms contribute to AIB1-mediated tumor formation. Cancer Res 70(10):4102-4111

22. Sugiura K, Stock CC (1952) Studies in a tumor spectrum. I. Comparison of the action of methylbis (2-chloroethyl)amine and 3-bis(2-chloroethyl)aminomethyl-4-methoxymethyl -5-hydroxy6-methylpyridine on the growth of a variety of mouse and rat tumors. Cancer. 5(2):382-402

23. Johnstone CN, Smith YE, Cao Y, Burrows AD, Cross RS, Ling X, Redvers RP, Doherty JP, Eckhardt BL, Natoli AL, Restall CM, Lucas E, Pearson HB, Deb S, Britt KL, Rizzitelli A, Li J, Harmey JH, Pouliot N, Anderson RL (2015) Functional and molecular characterisation of EO771.LMB tumours, a new C57BL/6-mouse-derived model of spontaneously metastatic mammary cancer. Dis Model Mech 8(3):237-251
24. Ewens A, Mihich E, Ehrke MJ (2005) Distant metastasis from subcutaneously grown E0771 medullary breast adenocarcinoma. Anticancer Res 25(6b):3905-3915

25. Yang Y, Yang HH, Hu Y, Watson PH, Liu H, Geiger TR, Anver MR, Haines DC, Martin P, Green JE, Lee MP, Hunter KW, Wakefield LM (2017) Immunocompetent mouse allograft models for development of therapies to target breast cancer metastasis. Oncotarget. 8(19):30621-30643

26. Miller FR, Miller BE, Heppner GH (1983) Characterization of metastatic heterogeneity among subpopulations of a single mouse mammary tumor: heterogeneity in phenotypic stability. Invasion Metastasis 3(1):22-31

27. Das N, Datta N, Chatterjee U, Ghosh MK (2016) Estrogen receptor alpha transcriptionally activates casein kinase 2 alpha: a pivotal regulator of promyelocytic leukaemia protein (PML) and AKT in oncogenesis. Cell Signal 28(6):675-687

28. Guy CT, Cardiff RD, Muller WJ (1992) Induction of mammary tumors by expression of polyomavirus middle T oncogene: a transgenic mouse model for metastatic disease. Mol Cell Biol 12(3): 954-961

29. Christenson JL, Butterfield KT, Spoelstra NS, Norris JD, Josan JS, Pollock JA, McDonnell D, Katzenellenbogen BS, Katzenellenbogen JA, Richer JK (2017) MMTV-PyMT and derived Met-1 mouse mammary tumor cells as models for studying the role of the androgen receptor in triple-negative breast cancer progression. Horm Cancer 8(2):69-77

30. Yang NC, Ho WM, Chen YH, Hu ML (2002) A convenient onestep extraction of cellular ATP using boiling water for the luciferinluciferase assay of ATP. Anal Biochem 306(2):323-327

31. Nautiyal J, Steel JH, Mane MR, Oduwole O, Poliandri A, Alexi X, Wood N, Poutanen M, Zwart W, Stingl J, Parker MG (2013) The transcriptional co-factor RIP140 regulates mammary gland development by promoting the generation of key mitogenic signals. Development. 140(5):1079-1089

32. Ciarloni L, Mallepell S, Brisken C (2007) Amphiregulin is an essential mediator of estrogen receptor alpha function in mammary gland development. Proc Natl Acad Sci U S A 104(13):5455-5460

33. Hutcheson IR, Knowlden JM, Madden TA, Barrow D, Gee JM, Wakeling AE, Nicholson RI (2003) Oestrogen receptor-mediated modulation of the EGFR/MAPK pathway in tamoxifen-resistant MCF-7 cells. Breast Cancer Res Treat 81(1):81-93

34. Massarweh S, Osborne CK, Creighton CJ, Qin L, Tsimelzon A, Huang S, Weiss H, Rimawi M, Schiff R (2008) Tamoxifen resistance in breast tumors is driven by growth factor receptor signaling with repression of classic estrogen receptor genomic function. Cancer Res 68(3):826-833

35. Jordan NJ, Gee JM, Barrow D, Wakeling AE, Nicholson RI (2004) Increased constitutive activity of $\mathrm{PKB} / \mathrm{Akt}$ in tamoxifen resistant breast cancer MCF-7 cells. Breast Cancer Res Treat 87(2):167-180

36. Adli M, Merkhofer E, Cogswell P, Baldwin AS (2010) IKKalpha and IKKbeta each function to regulate NF-kappaB activation in the TNF-induced/canonical pathway. PLoS One 5(2):e9428

37. Israel A (2010) The IKK complex, a central regulator of NFkappaB activation. Cold Spring Harb Perspect Biol 2(3):a000158

38. Kastrati I, Siklos MI, Calderon-Gierszal EL, El-Shennawy L, Georgieva G, Thayer EN et al (2016) Dimethyl fumarate inhibits the nuclear factor kappaB pathway in breast cancer cells by covalent modification of p65 protein. J Biol Chem 291(7):3639-3647

39. Nakshatri H, Bhat-Nakshatri P, Martin DA, Goulet RJ Jr, Sledge GW Jr (1997) Constitutive activation of NF-kappaB during progression of breast cancer to hormone-independent growth. Mol Cell Biol 17(7):3629-3639

40. Sas L, Lardon F, Vermeulen PB, Hauspy J, Van Dam P, Pauwels P et al (2012) The interaction between ER and NFKB in resistance to endocrine therapy. Breast Cancer Res 14(4):212 
41. Frasor J, El-Shennawy L, Stender JD, Kastrati I (2015) NFkappaB affects estrogen receptor expression and activity in breast cancer through multiple mechanisms. Mol Cell Endocrinol 418(Pt 3): 235-239

42. deGraffenried LA, Chandrasekar B, Friedrichs WE, Donzis E, Silva J, Hidalgo M, Freeman JW, Weiss GR (2004) NF-kappa B inhibition markedly enhances sensitivity of resistant breast cancer tumor cells to tamoxifen. Ann Oncol 15(6):885-890

43. Zhou Y, Yau C, Gray JW, Chew K, Dairkee SH, Moore DH et al (2007) Enhanced NF kappa B and AP-1 transcriptional activity associated with antiestrogen resistant breast cancer. BMC Cancer 7:59

44. Frasor J, Weaver AE, Pradhan M, Mehta K (2008) Synergistic upregulation of prostaglandin $\mathrm{E}$ synthase expression in breast cancer cells by 17 beta-estradiol and proinflammatory cytokines. Endocrinology. 149(12):6272-6279

45. O'Mahony F, Razandi M, Pedram A, Harvey BJ, Levin ER (2012) Estrogen modulates metabolic pathway adaptation to available glucose in breast cancer cells. Mol Endocrinol 26(12):2058-2070

46. Arias-Loza PA, Muehlfelder M, Pelzer T (2013) Estrogen and estrogen receptors in cardiovascular oxidative stress. Pflugers Arch 465(5):739-746

47. Lingappan K (2018) NF-kappaB in oxidative stress. Curr Opin Toxicol 7:81-86

48. Morgan MJ, Liu ZG (2011) Crosstalk of reactive oxygen species and NF-kappaB signaling. Cell Res 21(1):103-115

49. Tiwari BS, Belenghi B, Levine A (2002) Oxidative stress increased respiration and generation of reactive oxygen species, resulting in ATP depletion, opening of mitochondrial permeability transition, and programmed cell death. Plant Physiol 128(4):1271-1281

50. Kannan K, Jain SK (2000) Oxidative stress and apoptosis. Pathophysiology. 7(3):153-163

51. Pedram A, Razandi M, Wallace DC, Levin ER (2006) Functional estrogen receptors in the mitochondria of breast cancer cells. Mol Biol Cell 17(5):2125-2137

52. Nazarewicz RR, Zenebe WJ, Parihar A, Larson SK, Alidema E, Choi J, Ghafourifar P (2007) Tamoxifen induces oxidative stress and mitochondrial apoptosis via stimulating mitochondrial nitric oxide synthase. Cancer Res 67(3):1282-1290

53. Razmara A, Sunday L, Stirone C, Wang XB, Krause DN, Duckles SP, Procaccio V (2008) Mitochondrial effects of estrogen are mediated by estrogen receptor alpha in brain endothelial cells. J Pharmacol Exp Ther 325(3):782-790

54. Toneff MJ, Du Z, Dong J, Huang J, Sinai P, Forman J et al (2010) Somatic expression of PyMT or activated ErbB2 induces estrogenindependent mammary tumorigenesis. Neoplasia. 12(9):718-726

55. Waldmeier L, Meyer-Schaller N, Diepenbruck M, Christofori G (2012) Py2T murine breast cancer cells, a versatile model of TGF $\beta$-induced EMT in vitro and in vivo. PloS One 7(11): e48651-e

56. Guest SK, Ribas R, Pancholi S, Nikitorowicz-Buniak J, Simigdala N, Dowsett M, Johnston SR, Martin LA (2016) Src is a potential therapeutic target in endocrine-resistant breast cancer exhibiting low estrogen receptor-mediated transactivation. PLoS One 11(6): e0157397

57. Barletta F, Wong CW, McNally C, Komm BS, Katzenellenbogen B, Cheskis BJ (2004) Characterization of the interactions of estrogen receptor and MNAR in the activation of cSrc. Mol Endocrinol 18(5):1096-1108

58. Chakravarty D, Nair SS, Santhamma B, Nair BC, Wang L, Bandyopadhyay A, Agyin JK, Brann D, Sun LZ, Yeh IT, Lee FY, Tekmal RR, Kumar R, Vadlamudi RK (2010) Extranuclear functions of ER impact invasive migration and metastasis by breast cancer cells. Cancer Res 70(10):4092-4101

59. Vallabhaneni S, Nair BC, Cortez V, Challa R, Chakravarty D, Tekmal RR, Vadlamudi RK (2011) Significance of ER-Src axis in hormonal therapy resistance. Breast Cancer Res Treat 130(2):377385

60. Frei A, MacDonald G, Lund I, Gustafsson J-Å, Hynes NE, Nalvarte I (2016) Memo interacts with c-Src to control estrogen receptor alpha sub-cellular localization. Oncotarget. 7(35):56170-56182

61. Kumar R, Wang RA, Mazumdar A, Talukder AH, Mandal M, Yang Z, Bagheri-Yarmand R, Sahin A, Hortobagyi G, Adam L, Barnes CJ, Vadlamudi RK (2002) A naturally occurring MTA1 variant sequesters oestrogen receptor-alpha in the cytoplasm. Nature. 418(6898):654-657

62. Teyssier C, Le Romancer M, Sentis S, Jalaguier S, Corbo L, Cavailles V (2010) Protein arginine methylation in estrogen signaling and estrogen-related cancers. Trends Endocrinol Metab 21(3): 181-189

63. Gompel A, Somai S, Chaouat M, Kazem A, Kloosterboer HJ, Beusman I et al (2000) Hormonal regulation of apoptosis in breast cells and tissues. Steroids. 65(10-11):593-598

64. Wong WP, Tiano JP, Liu S, Hewitt SC, Le May C, Dalle S et al (2010) Extranuclear estrogen receptor-alpha stimulates NeuroD1 binding to the insulin promoter and favors insulin synthesis. Proc Natl Acad Sci U S A 107(29):13057-13062

65. Cheskis BJ, Greger J, Cooch N, McNally C, McLarney S, Lam HS et al (2008) MNAR plays an important role in ERa activation of Src/MAPK and PI3K/Akt signaling pathways. Steroids. 73(9-10): 901-905

66. Zhang QG, Raz L, Wang R, Han D, De Sevilla L, Yang F et al (2009) Estrogen attenuates ischemic oxidative damage via an estrogen receptor alpha-mediated inhibition of NADPH oxidase activation. J Neurosci 29(44):13823-13836

67. Menazza S, Sun J, Appachi S, Chambliss KL, Kim SH, Aponte A, Khan S, Katzenellenbogen JA, Katzenellenbogen BS, Shaul PW, Murphy E (2017) Non-nuclear estrogen receptor alpha activation in endothelium reduces cardiac ischemia-reperfusion injury in mice. J Mol Cell Cardiol 107:41-51

68. Liu S, Le May C, Wong WP, Ward RD, Clegg DJ, Marcelli M et al (2009) Importance of extranuclear estrogen receptor-alpha and membrane $\mathrm{G}$ protein-coupled estrogen receptor in pancreatic islet survival. Diabetes. 58(10):2292-2302

69. Hartman JL, Garvik B, Hartwell L (2001) Principles for the buffering of genetic variation. Science. 291(5506):1001-1004

70. Masel J, Siegal ML (2009) Robustness: mechanisms and consequences. Trends Genet 25(9):395-403

71. Nijman SM (2011) Synthetic lethality: general principles, utility and detection using genetic screens in human cells. FEBS Lett 585(1):1-6

72. Kelley R, Ideker T (2005) Systematic interpretation of genetic interactions using protein networks. Nat Biotechnol 23(5):561-566

73. Ghisletti S, Meda C, Maggi A, Vegeto E (2005) 17beta-estradiol inhibits inflammatory gene expression by controlling NF-kappaB intracellular localization. Mol Cell Biol 25(8):2957-2968

74. Nakshatri H, Goulet RJ Jr (2002) NF-kappaB and breast cancer. Curr Probl Cancer 26(5):282-309

75. Zhou Y, Eppenberger-Castori S, Marx C, Yau C, Scott GK, Eppenberger U, Benz CC (2005) Activation of nuclear factorkappaB (NFkappaB) identifies a high-risk subset of hormonedependent breast cancers. Int J Biochem Cell Biol 37(5):1130 1144

76. Welsh AW, Lannin DR, Young GS, Sherman ME, Figueroa JD, Henry NL, Ryden L, Kim C, Love RR, Schiff R, Rimm DL (2012) Cytoplasmic estrogen receptor in breast cancer. Clin Cancer Res 18(1):118-126

Publisher's Note Springer Nature remains neutral with regard to jurisdictional claims in published maps and institutional affiliations. 